\title{
CONTRIBUTION OF PHYSICAL DEVELOPMENT AND MUSCULAR STRENGTH TO THE MOTOR PERFORMANCE CAPACITY OF 7 TO 12 YEAR OLD BOYS
}

\author{
Janet B. TEEPLE, Ph.D., T. G. LOHMAN, Ph.D., J. E. MISNER, Ph.D., R. A. BOILEAU, Ph.D. \\ and B. H. MASSEY, Ph.D.
}

University of Illinois

\begin{abstract}
The contribution of selected physical development and muscular strength measures to general motor performance capacity was investigated in $\mathbf{5 5}$ seven to twelve year old boys. The physical development variables were height, body weight and fat-free body. Right and left hand strength, and static leg extension force of the right, left and both legs. simultaneously were used as measures of strength. The measures of general motor capacity were six field performance tests of the kind typically used by investigators and teachers including the softball throw, vertical jump, standing broad jump, shuttle run, 50 yard dash, and mile run. Data were analyzed by the method of least squares and constants fitted for height, body weight, fat-free weight and various measures of strength with chronological age held constant. Strength accounted for 18 to $\mathbf{4 3}$ percent of the variation in the children's motor performance score. Two measures of physical development, body weight and fat-free body weight together with age, were the dominant factors, contributing from 46 to 65 percent of the variation. Muscular strength and physical development measures together accounted for 57 to 70 percent of the variability in motor performance. For diagnostic and research purposes, measurement of physical development is an important consideration for proper interpretation of field tests of motor performance.
\end{abstract}

\section{Introduction}

Field tests of motor performance, for example, sit-ups, jumping, throwing, short and long runs, have long been used with children both for diagnostic and research purposes. Investigators have related performance of children on motor tests to academic achievement (2), mental retardation (21), socioeconomic level $(16,22)$, racial characteristics $(3,5)$, personality traits (23), self concept (25), attitude (6), social adjustment (7), strength (4), body composition (11, 14, 19) and the effectiveness of selected exercise and physical education programs $(10,12,13,20)$. Diagnostically they are used for delineating limitations in motor development and frequently serve as the basis for the grouping of children where physical development is an important consideration. The validity of utilizing such tests as measures of motor development is contingent upon availability of complete information regarding the sources of variation in performance scores and partialling out statistically, or otherwise, irrelevant contributing factors. It is obvious that performance on such tests is markedly influenced by such physical development factors as body composition and strength, factors which are beyond the child's control and not subject to easy manipulation. The purpose of this investigation was to obtain information regarding the contribution selected body composition and muscular strength factors make to the general motor performance scores of a group $(\mathrm{N}=55)$ of normally healthy boys in the 7 to 12 year old range.

This study was conducted at the Physical Fitness Research Laboratory, Department of Physical Education, University of IIlinois at Urbana-Champaign, Champaign, Illinois, 61820.

\section{Procedures}

Fifty-five boys, ranging in age from 7.1 to 12.1 years of age, were tested during the summer of 1971. In addition to chronological age, measurements of physical development included height, weight, and fat-free body weight. Fat-free body weight was estimated from the measurement of naturally-occurring radioactive potassium $\left({ }^{40} \mathrm{~K}\right)$ utilizing a whole-body liquid scintillation counter (24). From measurement of ${ }^{40} \mathrm{~K}$, body potassium was estimated and fat-free body was calculated assuming a constant potassium content of the fat-free body of $2.66 \mathrm{gm} / \mathrm{kg}$ (9). ${ }^{40} \mathrm{~K}$ is related to the amount of muscle and fat-free body and was hypothesized to provide a closer estimate of body muscle mass than height or weight and thus to have a greater association with motor performance involving movements of the body. All subjects were measured for fat-free body on two different occasions.

Measurements of static strength included three measures of leg strength (right leg, left leg and both legs) and two measures of grip strength (right and left). Each child was tested on two days, one week apart. On the first day the subject was introduced to the task and given several submaximal practice trials with each leg. Testing then began with the subject given 5 trials each with the right leg, left leg and both legs. The mean of the best two trials for each of the three tests was the final score. The subject was instructed to push as hard and fast as possible, after a starting signal was given, and to hold the contraction for approximately 3-1/2 seconds. The position of the subject was reclining with the back at an angle of 105 degrees. With the body strapped in 
position the subject pushed against a linear voltage differential transducer (LVDT) connected to a Daytronic amplifier and a Brush recorder. The paper speed was set at $100 \mathrm{~mm} / \mathrm{sec}$ and maximum force was measured as the highest point on the wave minus the baseline value. For the right and left grip the subjects were tested twice, on two separate occasions, with a Stoelting hand grip dynamometer.

The performance tests were administered on three different afternoons, with a maximum of two weeks between tests. The shuttle run, standing broad jump, and vertical jump were administered indoors in a gymnasium. The softball throw and the 50-yard dash were administered out-of-doors on a grass field. The mile run was administered on a 1/5 mile track. The shuttle run, standing broad jump, softball throw, and 50-yard dash test items were administered according to the AAHPER Youth Fitness Manual (1).

\section{Statistical Analysis}

Correlation coefficients and t-ratios were computed to assess week to week reliability of all tests. Zero order and partial correlation coefficients (with age held constant) were computed to show the relationships among all variables. The association of physical development and static strength with motor performance was measured by fitting constants using the least squares method, for age, height, weight, fat-free body and five strength measurements. Various combinations of these measures were used as independent variables to account for variations in motor performance scores by multiple regression analysis.

The use of multiple regression analysis in the predic- tion of motor performance scores is an advantage over linear regression analysis (use of one independent variable at a time) because the fitted constants (unstandardized regression coefficients) enable estimates of the association of each variable, with motor performance, holding constant the associations attributable to other independent variables. In the case of body composition and motor performance, the relation of body weight to jumping, ignoring variation in body fatness, is difficult to interpret because of the confounding influence of different amounts of m:uscle and fat in children of a given body weight. The use of weight and fat-free weight together in a multiple regression analysis shows the independent association of each variable on jumping. In combining all children aged 7 to 12 into one analysis, we have made the assumption that the relation between physical development variables and motor performance does not change significantly with primary school age children and therefore that similar regression coefficients would be found in each age.

\section{Results and Discussion}

The reliabilities of the physical growth and static strength measures (Table 1) were high with reliability coefficients ranging from 0.86 to 0.99 with only height reflecting a significant change in means. For most of the performance tests, small improvement was found from the first to the second to the third test, but this trend did not hold for all subjects. The best two performances were closely associated with each other for all tests except the shuttle run. Based on the performance test results (Table II), the decision was made to use the mean of the two best scores as the measure of maximal performance.

\section{TABLE I}

Reliability of Physical Growth and Static Strength Measurements of Boys 7.1 to 12.1 Years Old (N=55)

\begin{tabular}{|c|c|c|c|c|c|c|}
\hline & First & & Seco & & & \\
\hline & $x$ & S.D. & $x$ & S.D. & $r^{a}$ & $\mathbf{t}^{\mathbf{b}}$ \\
\hline Age, yr & 9.46 & 1.33 & - & - & - & _ \\
\hline $\mathrm{Ht}, \mathrm{cm}$ & 138.89 & 8.61 & 139.02 & 8.67 & .99 & $2.54^{d}$ \\
\hline $\mathrm{Wt}, \mathrm{Kg}$ & 32.71 & 7.29 & 32.92 & 7.15 & .99 & 1.77 \\
\hline$F F W, \mathrm{~kg}^{\mathrm{C}}$ & 26.59 & 5.24 & 27.00 & 5.04 & .91 & 1.41 \\
\hline Rt leg force, $\mathrm{kg}$ & 42.48 & 12.02 & 43.51 & 2.77 & .86 & 1.16 \\
\hline Lf leg force, $\mathrm{kg}$ & 43.72 & 13.97 & 44.50 & 13.20 & .88 & 0.88 \\
\hline Both legs, force, $\mathrm{kg}$ & 88.96 & 24.53 & 90.33 & 24.44 & .90 & 0.94 \\
\hline Rt grip, kg & 17.93 & 4.83 & 18.05 & 4.88 & .90 & 0.44 \\
\hline Left grip, $\mathrm{kg}$ & 16.58 & 4.56 & 16.74 & 4.73 & .89 & 0.56 \\
\hline
\end{tabular}

a Reliability coefficients between first and second tests

b t-test for changes in mean value of each measurement from first to second test

c Estimated from the mean of two days of measurement of naturally-occurring whole body potassium-40 radiation

d $p<.05$ 
TABLE II

Reliability of Field Tests of Motor Performance of Boys 7.1 to 12.1 Years Old ( $N=55$ )

First Test Second Test Third Test t-ratios

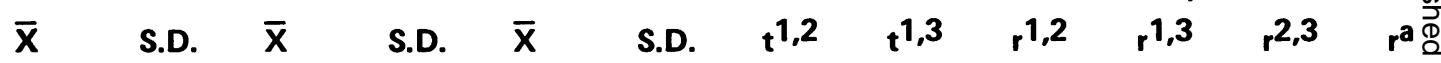

\begin{tabular}{|c|c|c|c|c|c|c|c|c|c|c|c|c|}
\hline $\begin{array}{l}\text { Jumping } \\
\text { Broad jump, in } \\
\text { Vertical jump, in }\end{array}$ & $\begin{array}{l}58.0 \\
10.4\end{array}$ & $\begin{array}{l}8.9 \\
2.5\end{array}$ & $\begin{array}{l}56.7 \\
10.8\end{array}$ & $\begin{array}{l}8.4 \\
2.5\end{array}$ & $\begin{array}{l}57.0 \\
10.7\end{array}$ & $\begin{array}{l}7.8 \\
2.6\end{array}$ & $\begin{array}{l}2.1^{b} \\
2.0^{b}\end{array}$ & $\begin{array}{l}1.2 \\
1.6\end{array}$ & $\begin{array}{l}.85 \\
.82\end{array}$ & $\begin{array}{l}.79 \\
.79\end{array}$ & $\begin{array}{l}.90 \\
.87\end{array}$ & $\begin{array}{l}\vec{\circ} \\
.94 \\
.9 \overrightarrow{\mathrm{g}}\end{array}$ \\
\hline $\begin{array}{l}\text { Running } \\
50 \text { yard, sec } \\
\text { Mile run, sec }\end{array}$ & $\begin{array}{r}9.1 \\
547.6\end{array}$ & $\begin{array}{r}0.8 \\
88.8\end{array}$ & $\begin{array}{r}9.1 \\
531.4\end{array}$ & $\begin{array}{r}0.8 \\
108.9\end{array}$ & $\begin{array}{r}9.0 \\
536.4\end{array}$ & $\begin{array}{r}0.8 \\
112.9\end{array}$ & $\begin{array}{l}0.4 \\
1.6\end{array}$ & $\begin{array}{l}1.0 \\
2.5^{b}\end{array}$ & $\begin{array}{l}.75 \\
.80\end{array}$ & $\begin{array}{l}.75 \\
.82\end{array}$ & $\begin{array}{l}.80 \\
.83\end{array}$ & $\begin{array}{l}.93 \bar{ె} \\
.93 \\
\end{array}$ \\
\hline $\begin{array}{l}\text { Throwing } \\
\text { Softball, } \mathrm{ft}\end{array}$ & 82.1 & 25.0 & 83.7 & 21.2 & 81.0 & 24.7 & 1.2 & 0.5 & .92 & .92 & .93 & \\
\hline $\begin{array}{l}\text { Agility } \\
\text { Shuttle run, sec }\end{array}$ & 12.1 & 1.0 & 11.9 & 0.8 & 11.5 & 0.7 & 1.5 & 5.2 & .61 & .62 & .56 & \\
\hline
\end{tabular}

a Correlation between the best and the second best of the three performance scores

b $\mathrm{p}<.05$

Zero order and partial correlation coefficients, holding age constant, computed among measures of physical development, static strength and motor performance are highest for the relation between individual measures of physical development and those of static strength (Table III). Of the physical development variables, fat-free body weight was somewhat more closely related to static strength than age, height and weight. The relationships of various strength tasks to individual physical development indicators when age was partialled out ranged from $r=$ .28 to .79 . These results are not altogether in agreement with others who have found moderate to high relations of measures of body physique and strength (17). Measures of physical development were not as closely correlated with field tests of motor performance, especially for tests of running and agility. With age partialled out, correlations ranged from -.01 to .66 for various motor performance tasks and measures of physical development. With the exception of the mile run, most of the partial correlations are low to moderate in agreement with the finding of others $(15,17)$ that no one measure of physical development is closely related to motor performance. 
TABLE III

Zero Order and Partial Correlations Among Measures of Physical Development and Static Strength and Field Tests of Motor Performance ${ }^{\mathrm{a}}$

$(N=55)$

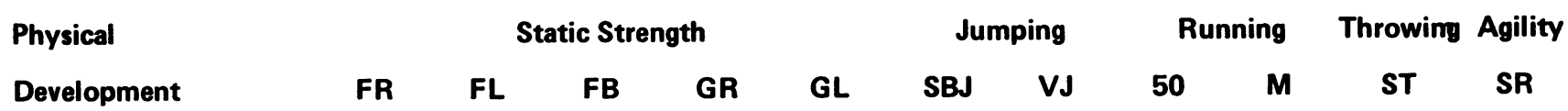

Zero Order Correlation Coefficientsb

\begin{tabular}{|l|c|c|c|c|c|c|c|c|c|c|c|}
\hline Age, months & .60 & .49 & .58 & .58 & .60 & .63 & .58 & -.37 &. .46 & .68 &. .46 \\
\hline Height, cm & .62 & .53 & .61 & .73 & .74 & .50 & .56 &. .29 & -.23 & .66 &. .37 \\
\hline Weight, kg & .53 & .52 & .52 & .76 & .65 & .14 & .20 & .08 & .23 & .30 &. .09 \\
\hline $\begin{array}{l}\text { Fat-free } \\
\text { bodyc, kg }\end{array}$ & .69 & .63 & .64 & .86 & .77 & .40 & .51 & -.25 &. .01 & .52 & -.36 \\
\hline
\end{tabular}

Partial Correlation Coefficients (holding age constant)

\begin{tabular}{|l|c|c|c|c|c|c|c|c|c|c|c|}
\hline Height, cm & .32 & .28 & .32 & .54 & .54 & .03 & .22 & -.01 & .21 & .29 & -.02 \\
\hline Weight, kg & .30 & .34 & .29 & .64 & .48 & -.33 & -.18 & .38 & .66 & .13 & .23 \\
\hline $\begin{array}{l}\text { Fat-free } \\
\text { bodyc, kg }\end{array}$ & .51 & .49 & .44 & .79 & .64 & .04 & .25 &. .05 & .38 & .20 & -.12 \\
\hline
\end{tabular}

a FR (force from right leg), FL (force from left leg), FB (force from both legs), GR (right grip strength), GL (left grip strength), SBJ (standing broad jump), VJ (vertical jump), 50 (time for 50 yard run), M (time for mile run), ST (softball throw), and SR (shuttle run).

b $r>.27$ significant at $p<.05$.

c Fat-free body estimated from whole-body $40 \mathrm{~K}$ radioactivity measurement.

Because children differ in their body composition at a given weight and age, the use of body composition measures along with height and weight might prove more useful in estimating motor performance. Thus, multiple regression formulae were used to predict motor performance from combinations of physical development and static strength measures (Table IV). Within the physical development variables, weight, and fat-free body each contributed significantly $(p<.01)$ to the prediction of motor performance and, together with age, accounted for $46 \%$ to $65 \%$ of the performance variability $(R=.681$ to .810$)$. In all cases the multiple correlations were obviously much larger when weight and fat-free body were included than were the zero order correlations for age with motor performance alone. This finding can be further amplified by analysis of the standardized regression coefficients (Table IV) which show that the contribution of body weight in each motor performance task was predominant, making negative relative contributions to the scores ranging from .713 (ST) to +1.060 (mile run). On the other hand, the next most important contribution in each motor performance score except that of the mile run was the fat-free body, making a positive relative contribution which ranged from .456 (ST) to .919 (VJ). The relative contribution of age to general motor performance, although important, appeared to be secondary to the importance of body composition in this study. These results differ from those of Montoye (15) and Espenschade (8), who suggested age alone was adequate for fitness test norms, and indicate that body weight and fat-free body measurements may improve the interpretation of motor performance evaluation in children. Static strength variables alone accounted for only $18 \%$ to $43 \%$ of motor performance variability, but in combination with physical development parameters contributed from $57 \%$ to $70 \%$ of the variance, again attesting to the relative importance of the body composition measures. Consequently, only $\mathbf{3 0}$ to $\mathbf{4 3}$ percent of the variability in motor performance reflected factors other than physical development and static strength. The influence of body weight and fat-free body weight is not surprising, since five of the six motor performance items involving moving the body either vertically or horizontally, in part supporting Reindau's (18) conclusions with adults. 
TABLE IV

Multiple Regression Analysis for Prediction of Motor Performance from Measures of Physical Development and Static Strength

Dependent Variables ${ }^{a}$

\begin{tabular}{|c|c|c|c|c|c|c|}
\hline \multirow{2}{*}{ Independent Variables } & \multicolumn{2}{|c|}{ Jumping } & \multicolumn{2}{|c|}{ Running } & \multirow{2}{*}{$\begin{array}{l}\text { Throwing } \\
\text { 6T }\end{array}$} & \multirow{2}{*}{$\begin{array}{l}\text { Agility } \\
\text { SR }\end{array}$} \\
\hline & SBJ & VJ & 50 & $\mathbf{M}$ & & \\
\hline \multicolumn{2}{|c|}{ Physical Development Only } & \multicolumn{5}{|c|}{ Standardized Regression Coefficients } \\
\hline Age & $.638^{\mathrm{C}}$ & $.419^{c}$ & $-.407^{c}$ & $-.663^{c}$ & $.445^{c}$ & $-.504^{c}$ \\
\hline Height & .045 & .149 & -.001 & -.269 & .401 & .161 \\
\hline Weight & $-.988^{c}$ & $-1.086^{C}$ & $1.327^{C}$ & $1.107^{C}$ & $-.746^{C}$ & $.981^{\mathrm{C}}$ \\
\hline Fat-free body & $.839^{\mathrm{C}}$ & $1.079^{\mathrm{C}}$ & $-1.164^{C}$ & -.347 & $.567^{\mathrm{C}}$ & $-1.049^{\mathrm{C}}$ \\
\hline$R$ & $.791^{\mathrm{C}}$ & $.810^{\mathrm{C}}$ & $.746^{\mathrm{C}}$ & $.790^{\mathrm{C}}$ & $.798^{\mathrm{C}}$ & $.681^{\mathrm{C}}$ \\
\hline S.E. of Estimate & 4.78 & 1.34 & .50 & 63.72 & 14.18 & .53 \\
\hline
\end{tabular}

Static Strength Only

Standardized Regression Coefficients

\begin{tabular}{|c|c|c|c|c|c|c|}
\hline Right leg (FR) & .465 & .580 & -348 & -.280 & .342 & -.204 \\
\hline Left leg (FL) & -.231 & $-.241 \mathrm{~b}$ & .210 & .252 & .018 & -.051 \\
\hline Both legs (FB) & .345 & .011 & -.149 &. .324 & -.100 & -.151 \\
\hline Right grip (GR) & -.361 & -.179 & .255 & .606 & -.337 & .077 \\
\hline Left Grip (GL) & .443 & .480 & -.423 &. .557 & $.746^{\mathrm{b}}$ & -.305 \\
\hline $\bar{R}$ & $.664^{\mathrm{C}}$ & $.637^{c}$ & $.458^{b}$ & .428 & $.659^{\mathrm{c}}$ & $.572^{\mathrm{c}}$ \\
\hline S.E. of Estimate & 5.89 & 1.78 & .67 & 94.77 & 17.88 & .60 \\
\hline
\end{tabular}

Physical Development and Static Strength

Standardized Regression Coefficients

\begin{tabular}{|c|c|c|c|c|c|c|}
\hline Age & $.507^{c}$ & $.366^{b}$ & -.323 & $-.557 c$ & $.452^{C}$ & $-.365^{b}$ \\
\hline Height & .038 & .114 & .002 & -.337 & .363 & .078 \\
\hline Weight & $-.876^{C}$ & $-1.016^{C}$ & $1.278^{C}$ & $1.060^{C}$ & $-.713^{C}$ & $.926^{C}$ \\
\hline Fat-free body & .525 & .919 & $-.841^{b}$ & .092 & .465 & -.478 \\
\hline Right leg & .126 & .163 & -.046 &. .047 & -.078 & .007 \\
\hline Left leg & .077 & .042 & -.028 & -.189 & .404 & -.255 \\
\hline Both legs & .161 & -.112 & -.042 & .027 & -.338 & .034 \\
\hline Right grip & -.106 & -.134 & -.121 & -.233 & -.258 & -.309 \\
\hline Left grip & .201 & .269 & -.199 & -.091 & $-.435^{b}$ & -.120 \\
\hline $\mathbf{R}$ & $.837^{C}$ & $.825^{C}$ & $.773^{\mathrm{C}}$ & $.825^{C}$ & $.838^{C}$ & .755 \\
\hline S.E. of Estimate & 4.50 & 1.36 & .50 & 61.79 & 13.54 & .50 \\
\hline
\end{tabular}

a SBJ (standing broad jump), VJ (vertical jump), 50 (time for 50 vard run), M (time for mile run), ST (softball throw), and SR (shuttle run).

b $p<.05$

c $p<.01$ 
The use of age alone for normative motor performance data makes the assumption that all children (sex differentiated) within an age grouping grow at the same rate, at least with respect to body weight and fat-free body weight, or ignores the obvious influence these factors have. An an example of the influence fat-free body weight has on motor performance, the hypothetical performance, based on group-determined regression equations, for a boy of the mean age, height, and weight for the present sample was computed for different fat-free weights. The predicted motor performance scores for this hypothetical boy holding constant age, height, and weight and theoretically varying fat-free body are shown in Table $V$. A rather large performance difference results from a mean difference of $15 \%$ in the fat-free body, particularly in the vertical jump, 50-yard run, and shuttie run. In these items the performance difference is greater than the group standard deviation and indicates marked classification differences based on AAHPER (1) age norms. Ten percent of this sample of children were less than $70 \%$ fat-free body and $34 \%$ were greater than $85 \%$ fat-free body.

TABLE V

Association of Fat-Free Body Content With Field Tests of Motor Performance

Field Tests of Motor Performance

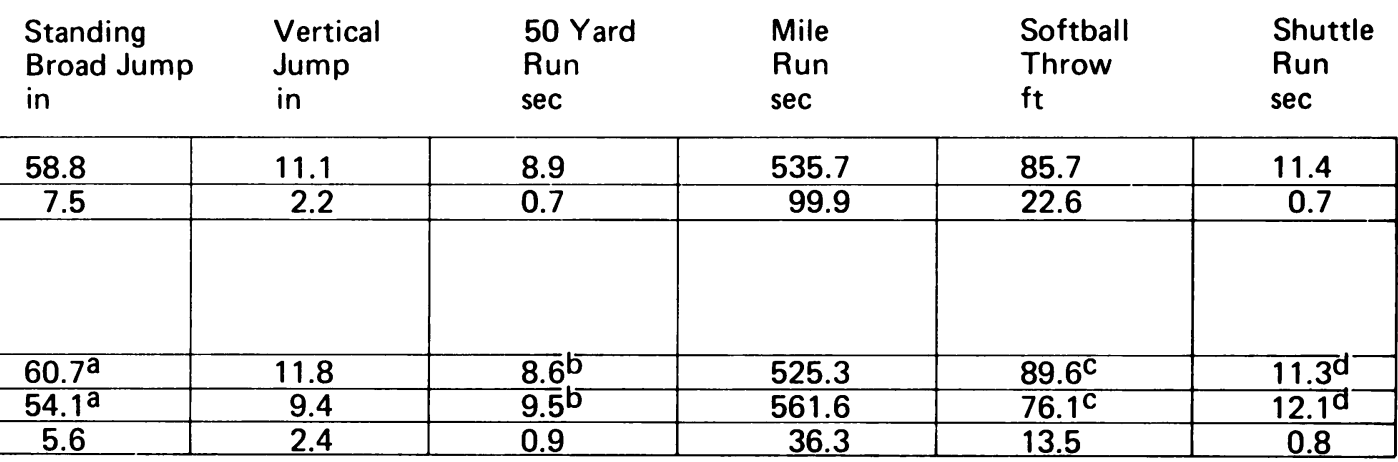

a Percentiles for age 10 from AAHPER (1) norms: $85 \%$ and $50 \%$, respectively.

b Percentiles for age 10 from AAHPER (1) norms: $60 \%$ and $28 \%$, respectively.

c Percentiles for age 10 from AAHPER (1) norms: $55 \%$ and $28 \%$, respectively.

d Percentiles for age 10 from AAHPER (1) norms: $78 \%$ and $50 \%$, respectively.

\section{Summary}

In summary, it was found that static strength is associated with variation in fat-free body weight, but that static strength alone is of limited value in predicting a child's motor performance. On the other hand, physical development measured in terms of age, height, weight, and fat-free body markedly influences motor performance, accounting for from $46 \%$ to $65 \%$ of the variation in the various motor performance measures. To not account for differences in physical development reflected in body composition measures when interpreting motor performance scores reflects an oversight with particularly serious implications for the child. The variability not accounted for by physical growth measures possibly is associated with dynamic strength, cardiorespiratory endurance, physical activity history, maturation, and perceptual-motor development. 


\section{REFERENCES}

1. American Association for Health, Physical Education and Recreation. A.A.H.P.E.R. Youth Fitness Test Manual. Washington, D.C., 1958.

2. ARNETT, C. Interrelationships between selected physical variables and academic achievement of college women. Research Quarterly, 1968, 39, 227-330.

3. BARKER, D. G. and PONTHIEUX, N. A. Partial relationships between race and fitness with socioeconomic status controlled. Research Quarterly, 1968, 39, 773-775.

4. BERGER, R. A. and MABEE, D. Relationship of the A.A.H.P.E.R. Youth Fitness Test in total dynamic strength. Research Quarterly, 1967, 38, 314-315.

5. BERGER, R. A. and PARADIS, R. L. Comparison of physical fitness scores of white and black seventh grade boys of similar socioeconomic level. Research Quarterly, 1969, 40, 666-669.

6. CAMPBELL, D. E. Relationship between scores on the wear attitude inventory and selected physical fitness scores. Research Quarterly, 1969, 40, 470-474.

7. COLEMAN, J. C., KEOGH, J. R. and MANSFIELD, J. Motor performance and social adjustment among boys experiencing serious learning difficulties. Research Quarterly, 1963, 34, 516-517.

8. ESPENSCHADE, A. A. Restudy of relationships between physical performances of school children and age, height, and weight. Research Quarterly, 1963, 34, 144-153.

9. FORBES, G. B. Growth of the lean body mass on man. Growth, 1972, 36, 325-338.

10. FRANKS, B. D. and MOORE, G. C. Effects of calisthenics and volleyball on the A.A.H.P.E.R. fitness test and volleyball skill. Research Quarterly, 1969, 40, 288-292.

11. ISMAIL, A. H., CHRISTIAN, J. E. and KESSLER, W. V. Body composition relative to motor aptitude for preadolescent boys. Research Quarterly, 1963, 34, 462-470.

12. KNUTTGEN, H. G. Comparison of fitness of Danish and American school children. Research Quarterly, 1961, 32 , 190-196.

13. KNUTTGEN, H. G. and STEENDAHL, K. Fitness of Danish school children during the course of one academic year. Research Quarterly, 1973, 34, 34-40.

14. LEEDY, H. E., ISMAIL, A. H., KESSLER, W. V., and CHRISTIAN, J. E. Relationships between physical performance items and body composition. Research Quarterly, 1965, 36, 158-163.

15. MONTOYE, H. J., FRANTZ, M. E., and KOZAR, A. J. 'The value of age, height and weight in establishing standards of fitness for children. Journal of Sports Medicine, 1972, 12, 174-179.

16. PONTHIEUX, N. A. and BARKER, D. G. Relationship between socioeconomic status and physical fitness measures. Research Quarterly, 1965, 36, 464-467.

17. RARICK, G. L. (Ed.) Physical Activity: Human Growth and Development. New York: Academic Press, 1973.

18. RIENDEAU, R. P., WELCH, B. E., CRISP, C. E., CROWLEY, L. V., GRIFFIN, A. E. and BROCKETT, J. E. Relationships of body fat to motor fitness test scores. Research Quarterly, 1958, 29, 200-203.

19. RICCI, B. For a moratorium on "physical fitness" testing. Journal of Health, Physical Education and Recreation, 1970, 28-30.

20. ROTHERMEL, B. L., POLLACK, M. L. and CURETON, T. K. A.A.H.P.E.R. physical fitness test score changes resulting from an eight-week sports and physical fitness program. Research Quarterly, 1968, 39, 1127-1129. 
21. SENGSTOCK, W. L. Physical fitness of mentally retarded boys. Research Quarterly, 1966, 37, 113-120.

22. THOMAS, J. R., COTTON, D. J. and BIASIOTTO, J. Physical fitness of low socioeconomic level white males. American Corrective Therapy Journal, 1973, 27, 46-48.

23. TILLMAN, K. Relationship between physical fitness and selected personality traits. Research Quarterly, 1967, 37. 483-489.

24. TWARDOCK, A. R., LOHMAN, T. G., SMITH, G. S. and BREIDENSTEIN, B. C. The Illinois Animal Science Counter: performance characteristics and animal radioactivity measurement procedures. Journal of Animal Science, $1966,25,1209-1217$.

25. YEATTS, P. P. and GORDON, I. J. Effects of physical education taught by a specialist on physical fitness and self-image. Research Quarterly, 1968, 39, 766-770.

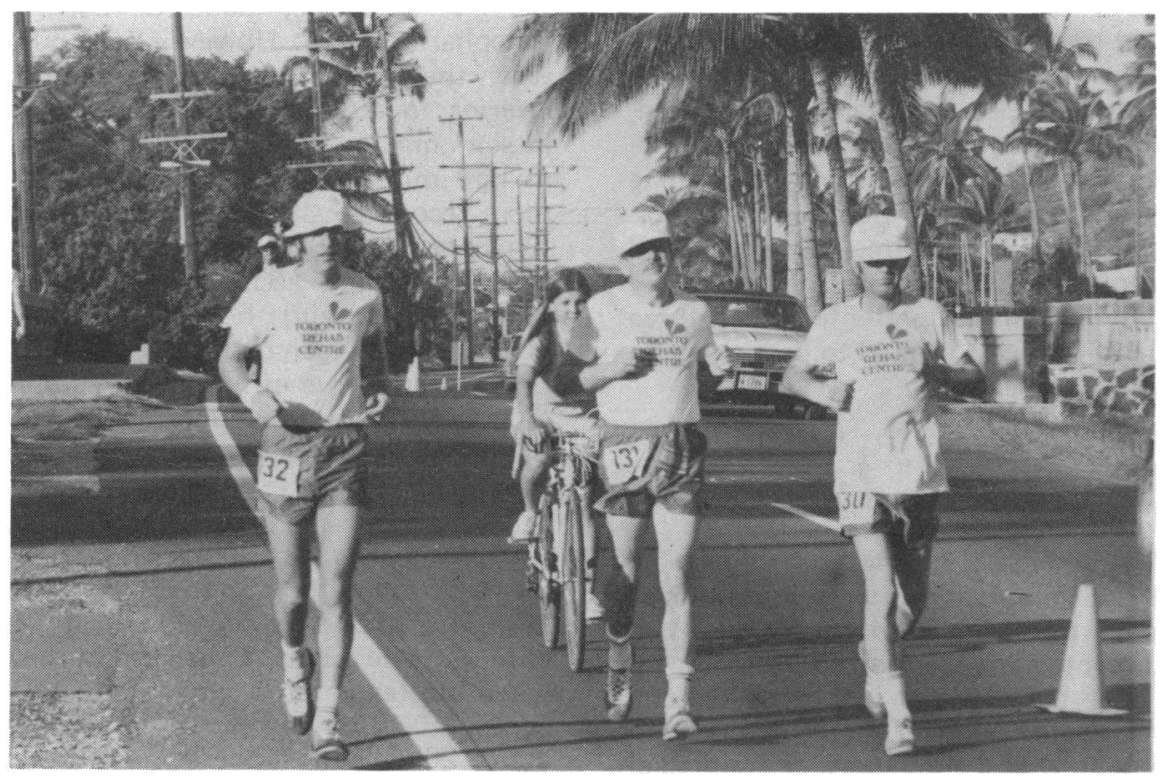

Figure 1: KAVANAGH and SHEPHARD (see.next article)

Rehabilitation of post-coronary patients. 